\title{
Ruptured Cornual Monochorionic Monoamniotic Twin Ectopic Pregnancy: A Case Report
}

\author{
$*+$ B.T UTOO and **S.O OJO \\ *Obstetrics \& Gynaecology department, Jos University Teaching Hospital. **Maternity unit, Holy \\ family Hospital Ikom, Cross-River State, Nigeria.
}

†Correspondence: Dr B.T UTOO

P O Box 10480, University of Jos, Jos, Plateau State, Nigeria.

E-Mail: bernardutoo@yahoo.com GSM:08033725168

\begin{abstract}
Cornual pregnancy is a rare form of ectopic pregnancy that usually leads to uterine rupture with resultant life threatening haemorrhage. The mortality rate of interstitial pregnancies is more than twice that of other tubal pregnancies. Monochorionic monoamniotic twin gestation is also a rare form of twin pregnancy. We report a case of ruptured cornual monochorionic monoamniotic twin pregnancy at 9 weeks 2 days. The patient's diagnosis was aided by ultrasound scan and she underwent emergency laparatomy at which cornual resection and preservation offertility was done. A high index of suspicion for ectopic pregnancy in women of reproductive age who presented with history of amenorrhea and lower abdominal pains could prove useful in making a diagnosis of ectopic pregnancy. The usefulness of ultrasonography has also been demonstrated.
\end{abstract}

Key Words: Monochorionic monoamniotic, cornual, twin, ectopic, pregnancy.

\section{Introduction}

We present two rare clinical conditions in gynaecological practice. Cornual pregnancy accounts for $1-2 \%$ of ectopic pregnancies and $20 \%$ of cases that advance beyond 12 weeks of gestation end in rupture ${ }^{1,2,3}$. Uterine rupture may result in massive bleeding due to the richness of the local vascularization through the branches of the uterine and ovarian arteries leading to a higher mortality rate $^{2}$

Monochorionic monoamniotic twin (MoMo) occurs in one of 10,000 pregnancies. It constitutes $1 \%$ of monozygotic twining in which case cell division occurs between 8 to 13 days post fertilization ${ }^{4}$. Cord entanglement, malformations, twin-to-twin transfusion syndrome (TTS) and prematurity are responsible for their high morbidity and mortality ${ }^{5}$.

Several risk factors for ectopic pregnancy have been identified including pelvic inflammatory disease, smoking, IUCD, and previous ectopic. Other factors such as age, surgical history, obstetric history, progesterone only pills, and in utero DES exposure are thought to be involved ${ }^{6,7,8}$.

Until recently cornual ectopic or interstitial pregnancies have been treated by laparatomy with cornual excision or hysterectomy. However, increasingly there have been attempts to add laparoscopic conservative management as a treatment option. A rare form of twin ectopic, its management with review of relevant literature has been presented.

\section{Case Report}

Miss PO was a 28 year old primiparous lady who presented to the gyneacology unit of the hospital with a history of lower abdominal pains. She was said to have collapsed shortly thereafter. She had no history of vaginal bleeding. Her last menstrual period was sometimes in August 2010. She was therefore approximately 8 weeks amenorrheic. She attained menarche at the age of 16 years. She menstruates between 3 to 4 days in a 28 day menstrual cycle with no associated dysmenorrhea, or menorrhagia. She was aware of contraception but never used any method in the past and was not on any method at the time of presentation.

Her last child birth was 9 years prior to presentation. She had two induced abortions at 8 weeks each in chemists with no reportable post abortal complication. She had however been treated for pelvic infections with antibiotics in the past. She was treated for typhoid and malaria by the general medical practitioner at the MOPD wing of the hospital a week prior to present complaint.

On examination, she was acutely ill-looking, pale, afebrile and not jaundiced. Her lung fields were clinically clear. The pulse rate was 96 beats per minuite.The blood pressure was $140 / 70 \mathrm{mmHg}$. Only the first and second heart sounds were heard 
on auscultation. The abdomen was full and moved with respiration. No surgical scarification marks were seen. There was marked suprapubic tenderness. The vulva and vagina were grossly normal. The uterus was slightly bulky. She had cervical motion tenderness.

An impression of a suspected ectopic pregnancy to keep in view twisted ovarian cyst was made. A urine HCG test done was positive. An ultrasound scan revealed a bulky empty uterus with endometrial plate visualized. The pouch of Douglass had moderate fluid collection. There was a right adnexal gestational sac located at the cornual with thin myometrial layer surrounding it. The sac contained monochorionic monoamniotic viable twin fetuses. The crown rump length (CRL) for each fetus was $31.0 \mathrm{~mm}$. Their gestational ages (GA) were 9weeks 2 days. Their expected date of delivery (EDD) was 10/05/2010.

Her haemogram showed a haemoglobin concentration of $8 \mathrm{~g} / \mathrm{dl}$, white blood cell count (WBC) of $5.6 \times 10^{9} / \mathrm{L}$, Neutrophils $54 \%$, Lymphocytes $40 \%$, Eosinophils 4\%, Monocytes $2 \%$. Her blood test for HIV was negative. Urinalysis showed PH-7.0, protein+, glucose-, Bilirubin +, Ascorbic acid +. Malaria parasites test showed positive.

An intravenous access was achieved with a size G18 cannula.Intravenous fluids 5\% dextrosesaline was administered. A Foley's size 18 urethra catheter was inserted and attached to a urine bag. Two units of blood were grouped and crossmatched. She was therefore prepared for an emergency laparatomy .Through a midline subumbilical incision; the abdominal-pelvic cavity was accessed. The intra-operative findings included, a haemoperitoneum of $200 \mathrm{mls}$, mild filmy pelvic adhesions, and right ruptured cornual ectopic gestation. The right and left ovaries/left tube was grossly normal.

A right cornual resection and the stump ligated with polygalactin sutures size 2 were done. The abdominal-pelvic cavity was lavaged with 1 liter of $0.9 \%$ warm normal saline solution. The abdomen was closed in layers. She had post operative treatment with intravenous fluids, Augmentin, metronidazole and diclofenac injections. She commenced oral feeds on the second postoperative day.

Antibiotics were converted to orals and were administered for a week. The urethral catheter was discontinued 24hours after surgery. She had a stable post operative period. She was given haematinics and discharged home on the $7^{\text {th }}$ post operative day. She was reviewed in the gynaecology unit two weeks later. There was no abnormality on general examination. Her haemoglobin concentration was $9 \mathrm{~g} / \mathrm{dl}$. She was reassured and encouraged to continue on haematinics and contraception.

\section{Discussion}

The aetiologic factors for cornual ectopic pregnancy are pelvic inflammatory disease, turmor, a high number of transferred embryos, and a transfer near the uterine horn, and excessive pressure on the syringe during the transfer during assisted reproduction or difficulties during the ET procedure ${ }^{1,6,7,9,10}$. Bilateral salpingectomy is likely to be another factor for cornual ectopic pregnancy. For non salpingectomised patients, peri-and intra tubular adhesions, related or not related to endometriosis are additional risk factors ${ }^{1}$.

In the case presented above pelvic inflammatory disease could likely have been the predisposing factor for ectopic pregnancy. She was treated in the past with antibiotics in a private clinic. Her age and the fact that she is in the southern region of the country where the incidence of twining is high could have contributed to the twin pregnancy she had.

Cornual pregnancy is diagnosed with ultrasonographic criteria in the presence of a positive HCG level indicating pregnancy. These criteria which were fulfilled in our patient include: visualization of no gestational sac within the uterine cavity, an asymmetrically located gestational sac within the uterus, a thin myometrial layer surrounding the gestational sac ${ }^{1,11}$. The patient was haemodynamically stable at presentation so the USS findings were very helpful in making a diagnosis.

Cornual pregnancies often rupture later than other tubal pregnancies because the myometrium is more distensible than the fallopian tube. The intramural tubal segment lies in close proximity to the uterine artery and interstitial tubal rupture usually results in brisk haemorrhage and a higher maternal morbidity and mortality rates than other ectopic pregnancies. Uterine rupture in this case occurred at 9weeks 2 days probably because this was a twin gestation and as such the gestational sac was bigger than usual. The uterine rupture was an intra operative finding suggesting that it might have occurred shortly before surgery. The patient was haemodynamically stable at presentation and haemoperitoneum was not diagnosed at USS. 
In an unruptured cornual pregnancy, a variety of conservative management options such as medical with methotrexate applied by parenteral route or directly injecting methotrexate or potassium chloride into the cornual gestational sac with ultrasound guidance, laparoscopic cornual resection, and selective uterine artery embolization when conservative treatment with uterine preservation is desired $^{1,3,7}$. A major advantage of conservative treatment is the preservation of fertility and a key disadvantage is the risk of uterine rupture during the subsequent pregnancy. In our patient, cornual resection was chosen at laparatomy in order to preserve fertility as she was a primiparous single lady.

\section{Conclusion}

This case has clearly brought to fore the need to have a high index of suspicion for ectopic pregnancy whenever a woman of reproductive age group presents to the clinic with a history of amenorrhea and lower abdominal pain with or without vaginal bleeding, even if she is haemodynamically stable. The use of imaging procedures such as ultrasonography where the equipment and expertise exist is encouraged.

\section{References}

1. U Ince, MA Osmanagaoglu and H Boskaya. A ruptured cornual ectopic pregnancy at 18 weeks gestation: A case report. The internet Journal of Gynaecology and Obstetrics; 2008; 9(2).

2. Jayanta C, Asma A, Fatai AS, Laure I, David G. A rare sequel following cornual ectopic pregnancy: a case report. BMJ case Reports, 2009; 10.1614.

3. L Cordero, A Franco and SD Joy. Monochorionic monoamniotic twins: neonatal outcome. J Perinatol, 2006; 26:170-175.

4. WA Grobman and MP Milad. Conservative laparoscopic management of a large cornual ectopic pregnancy. Human Reproduction, 1998; 13(7): 2002-2004.

5. Nkyekyer K. Multiple pregnancy. In EY Kwawukume and EE Emuveyan (Eds). Comprehensive Obstetrics in the tropics. First edition. Asante \& Hittscher printing press Limited, 2002: 162-172.

6. Jean B, Joel C, Taraneh S, Jean- Luc P, Herve F, Laurent $\mathrm{G}$ and Nadine JS. Risk factors for ectopic pregnancy: a comprehensive analysis based on large case-control population-based study in France. Am J Epidemiol, 2002; 157(3): 185-194.

7. JJ Beltman and CJM Groot. Cornual pregnancy as a complication of the use of a levenorgestrel intrauterine device: a case report. Journal of medical case reports.2009; 3: 8387.
8. Ankum WM, Mol BW, Vanderveen F, Bossuyt PM. Risk factors for ectopic pregnancy: a meta-analysis. Fertil Steril, 1997; 67(4): 791-792.

9. Weigert M, Gruber D, Pernicka E, Bauer P, Feichtinger W. Previous tubal ectopic pregnancy raises the incidence of repeated ectopic pregnancies in in vitro fertilizationembryo transfer patients. J Assist Reprod Genet, 2009; 26(1): 13-17.

10. Lee JD, Chang SY, Chang MY, Lai YM, Soong YK. Simultaneous bilateral tubal pregnancies after in vitro fertilization and embryo transfer: report of a case. J Formos Med Assoc.1992; 91(1): 99-101.

11. TEAckmermman, CS Levi, SM Dashefssky, SC Holt and DJ Lindsay. Interstitial line: Sonographic findings in interstitial (cornual) ectopic pregnancy. Radiology, 1993; 189:83-87.

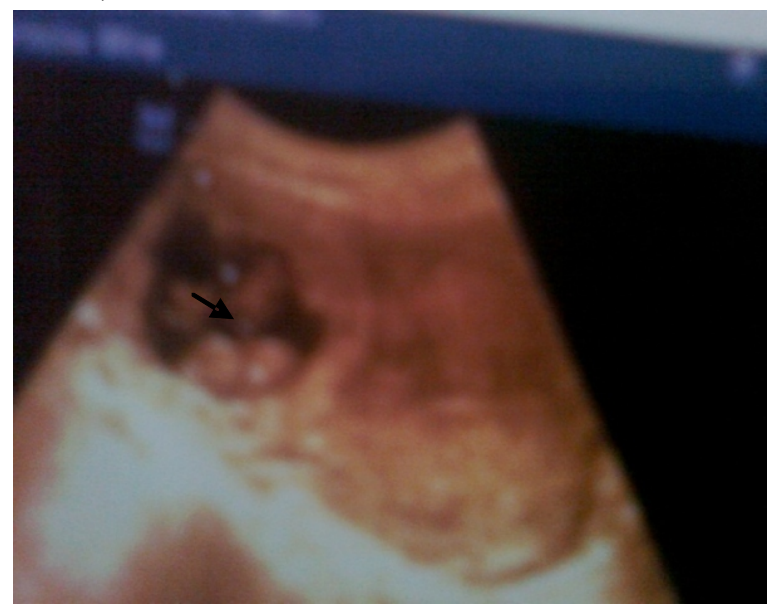

Figure 1: Ultrasound scan demonstrating cornual monochorionicmonoamniotic twin gestation. Note the empty uterus.

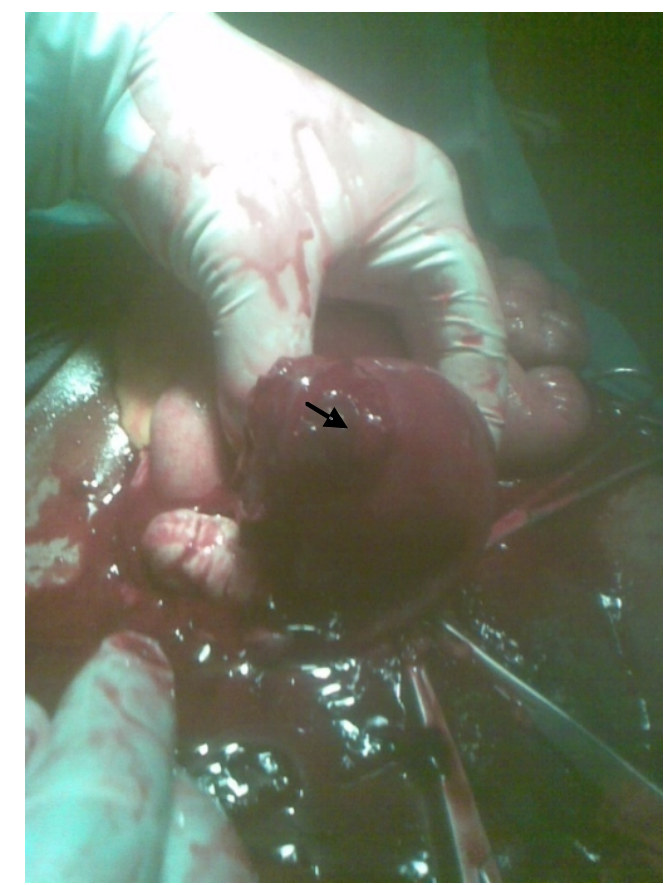

Figure 2: Ectopic gestational sac demonstrated at surgery. 